\title{
FAKTOR-FAKTOR YANG BERHUBUNGAN DENGAN KECELAKAAN KERJA PADA PENGRAJIN GONG DI DUSUN TIHINGAN, KABUPATEN KLUNGKUNG \\ TAHUN 2018
}

\author{
Juliana $^{1}$, I Nyoman Purna ${ }^{2}$, I Ketut Aryana ${ }^{3}$ \\ Politeknik Kesehatan Denpasar
}

\begin{abstract}
The occupational health and safety in the management of hazard and so that the environment is very little risk of the creation of a positive a safe and healthy work. The puspose of this research to know the factors that relating to occupational accident on a craftsman gong in Tihingan hamlet, Klungkung. The kind of research used in research survey observational crossectional research study to a draft. Population in this research is all workers a craftsman gong in Tihingan hamlet, Klungkung many as 60 home industry were selected from 96 research workers. Use chi-square data available for analysis. The results of the research obtained which are not there was a correlation $(P$ value $>0,050)$ between the ages $(0,301)$, education $(0,497)$, the temperature $(0,094)$, lighting $(0,714)$, and influential factor equipment $(0,118)$ by occupational accident and it can be seen there was a correlation $(P$ value $<0,050)$ between period of employment $(0,000)$, a self protection $(0,039)$, and noise $(0,010)$ by occupational accident on a craftsman gong in Tihingan hamlet, Klungkung. Increase the prevention of the workers risk of occupational accident using the self protection a complete to improve security and safety.
\end{abstract}

Keywords: Occupational Accident

Pembagunan ekonomi di
Indonesia dikembangkan melalui
banyak bidang, diantaranya
pariwisata, industri, kesenian,
pertambangan dan lain-lain. Bali
merupakan salah satu daerah yang
mempunyai keberagaman budaya
yang menarik minat banyak
wisatawan, sehingga menciptakan
lapangan kerja bagi masyarakat di
bidang pariwisata, kesenian dan
salah satunya bidang industri rumah
tangga.
Pengelompokan jenis industri
berdasarkan jenis dan modal kerja
yang digunakan, yakni industri besar
(industri dasar), industri menengah
(aneka industri), dan industri kecil
(home industry). Industri kecil
dengan biasanya menggunakan

teknologi sederhana/tradisional dengan modal yang relative terbatas merupakan industri yang bergerak di bidang informal, dimana pekerja pada industri tersebut pada umumnya belum mendapatkan pelayanan kesehatan kerja $^{1}$

Salah satu industri rumah tangga yang perlu mendapat perhatian ialah industri pembuatan gong yang ada di Desa Tihingan, Kabupaten Klungkung. Sebagian besar mata pencaharian masyarakat berasal dari hasil pembuatan gong yang masih di kerjakan dengan alat seadanya. Dalam proses pembuatan gong yang dilakukan pekerja terdapat banyak risiko timbulnya kecelakaan kerja karena karena pekerja dekat dengan sumber bahaya 
paparan suhu panas dan kebisingan, dan memerlukan pencahayaan yang cukup, serta penggunaan APD yang kurang aman dan juga faktor peralatan serta bahan yang digunakan.

Dari hasil observasi awal yang telah dilakukan di tiga home industry kerajinan gong yang ada di Dusun Tihingan terdapat beberapa faktor yang dapat menimbulkan terjadinya kecelakaan kerja, seperti penempatan peralatan yang berserakan, pekerja yang tidak menggunakan Alat Pelindung Diri (APD) saat bekerja, dan jarak pekerja yang dekat dengan sumber bahaya. Sedangkan untuk jenis kecelakaan kerja yang pernah dialami yaitu terjatuh, tertimpa benda, tergores, tertusuk, terbakar, dan gerakan-gerakan yang melebihi kemampuan karena menggunakan alat yang berat.

Dari uraian diatas maka yang menjadi perumusan masalah dalam penelitian ini adalah "Apa saja faktor-faktor yang berhubungan dengan kecelakaan kerja pada pengrajin gong di Dusun Tihingan, Kabupaten Klungkung Tahun 2018?".

Tujuan umum dari penelitian ini adalah Untuk mengetahui faktorfaktor yang berhubungan dengan kecelakaan kerja pada pengrajin gong di Dusun Tihingan, Kabupaten Klungkung Tahun 2018.

\section{METODE PENELITIAN}

Jenis penelitian yang dilakukan termasuk dalam penelitian survey obeservasional dengan rancangan penelitian crossectional study (studi potong melintang) dimana variable bebas (independent variable) dan variable terikat (dependent variable) diukur atau dikumpulkan secara simultan atau dalam waktu yang sama. Penelitian ini telah dilaksanakan di tempat kerja pengrajin gong yang berada di Dusun Tihingan, Kabupaten Klungkung pada bulan Juni-Juli 2018. Populasi dalam penelitian ini adalah semua pekerja pengrajin gong yang ada di Dusun Tihingan, Kabupaten Klungkung yaitu sebanyak 60 Home Industry dengan masing-masing berkisar 3 sampai 5 pekerja. Maka untuk menentukan jumlah sampel yang akan dipakai dalam penelitian ini digunakan rumus cross sectional menurut Snedecor GW \& Cochran WG $(1967)^{2}$ besar populasi (N) tidak diketahui, sebagai berikut:

$\mathrm{n}=\frac{\mathrm{Z}^{2} P(1-P)}{d^{2}}$

Keterangan:

$\mathrm{n} \quad=$ Jumlah sampel minimal yang diperlukan

$\mathrm{Z}=$ score $\mathrm{Z}$, berdasarkan nilai $a$ yang diinginkan $(1,96)$

$a \quad=$ derajat kepercayaan

$d \quad=$ toleransi kesalahan $10 \%$ $(0,1)$

$\mathrm{p} \quad=$ proporsi kasus yang diteliti dalam populasi. Jika $\mathrm{p}$ tidak diketahui maka digunakan $\mathrm{p}$ terbesar yaitu $\mathrm{p}=0,5$

Besarnya sampel dalam penelitian ini adalah:

$$
\begin{aligned}
& \mathrm{n}=\frac{\mathrm{Z}^{2} P(1-P)}{d^{2}} \\
& \mathrm{n}=\frac{1,96^{2} 0,5(1-0,5)}{0,1^{2}} \\
& \mathrm{n}=\frac{3,8416 \times 0,25}{0,01} \\
& \mathrm{n}=\frac{0,9604}{0,01} \\
& \mathrm{n}=96,04 \sim 96 \text { pekerja }
\end{aligned}
$$

Pengambilan sampel dilakukan dengan teknik Multiple Stage Sample dimana sampel ditarik dari kelompok populasi, tetapi tidak semua anggota kelompok populasi menjadi anggota sampel, hanya sebagian dari anggota sub populasi 
menjadi anggota sampel $^{2}$ (Nazir, 2003). Pengambilan sampel dilakukan dengan menggunakan sistem undian dengan menyiapkan gulungan kertas sehingga peneliti akan mendapatkan pekerja yang akan dijadikan sebagai sampel sesuai dengan nomor urut yang didapat dari undian. Sampel yang akan diambil sebanyak 96 pekerja dari 30 Home Industry yang ada di Dusun Tihingan, Kabupaten Klungkung yang diambil dengan menggunakan teknik Multiple Stage Sample.

Jenis data yang dikumpulkan dalam penelitian ini adalah data primer dan sekunder. Data primer berupa data pengukuran suhu, kebisingan dan pencahayaan yang terdapat pada lembar observasi serta kuesioner yang telah diisi oleh responden yang dikumpulkan peneliti. Data sekunder berupa data jumlah pengrajin gong yang ada di Dusun Tihingan, Kabupaten Klungkung, buku-buku dan jurnal dari penelitian sebelumnya yang terkait dengan penelitian.

Pengumpulan data dalam penelitian ini menggunakan tiga cara yaitu pengukuran suhu paparan menggunakan alat thermometer, kebisingan menggunakan alat sound level meter dan pecahayaan lingkungan kerja menggunakan alat lux meter, pengisian lembar observasi oleh peneliti, dan pengisian kuesioner oleh pekerja sebagai responden dalam penelitian. Data dianalisis menggunakan uji chisquare, uji signifikan menggunkaan

Distribusi frekuensi responden berdasarkan faktor manusia, faktor lingkungan kerja, dan faktor peralatan tahun 2018

menunjukkan hasil bahwa pada responden yang memiliki umur $<35$ tahun sebanyak 15 pekerja $(15,6 \%)$. batas kemaknaan $\alpha=0,05$ dengan taraf signifikan $95 \%$. Hasil uji ChiSquare dilihat dengan nilai p. Jika nilai $\mathrm{p}<0,05$ maka Ho ditolak dan $\mathrm{Ha}$ diterima, yang menyimpulkan bahwa terdapat hubungan antara variabel bebas (umur, masa kerja, pendidikan, APD, suhu, kebisingan, pencahayaan, dan faktor peralatan) dengan variabel terikat (kecelakaan kerja) pada pengrajin gong di Dusun Tihingan, Kabupaten Klungkung.

\section{HASIL DAN PEMBAHASAN}

Hasil. Jumlah penduduk di Desa Tihingan sebanyak 3.789 jiwa dari $880 \mathrm{KK}$ dengan uraian penduduk laki-laki 1.913 jiwa dan penduduk perempuan 1.876 jiwa. Jenis mata pencaharian pokok penduduk Desa Tihingan terdiri dari petani, buruh tani, pegawai negeri sipil, pengarjin industri rumah tangga, pedagang, peternak, montir, TNI, dan lain sebagainya. Salah satu jenis mata pencaharian pokok penduduk Desa Tihingan yaitu pengrajin industry rumah tangga, khususnya pengrajin gong. Kurang lebih terdapat 60 home industry

Jenis kecelakaan kerja

Pengukuran jenis kecelakaan
kerja didapatkan dari hasil
wawancara dengan responden yang
masuk dalam tiga kategori. Adapun
distribusi frekuensi jenis kecelakaan
kerja responden yaitu sebagai
berikut:

\section{Analisis univariat}

Responden dengan masa kerja baru sebanyak 17 pekerja $(17,7 \%)$. Responden dengan kategori pendidikan SD sebanyak 28 pekerja (29,2\%). Responden dengan kategoti penggunaan APD tidak lengkap sebanyak 83 pekerja $(86,5 \%)$. 
Responden dengan kategori suhu memenuhi syarat sebanyak 59 pekerja $(61,5 \%)$. Responden dengan kategori kebisingan memenuhi syarat sebanyak 82 pekerja $(85,4 \%)$. Responden dengan kategori pencahayaan memenuhi syarat sebanyak 30 pekerja $(31,3 \%)$. Dan responden dengan kategori peralatan

Kejadian kecelakaan kerja ringan dengan kategori umur $<35$ tahun sebanyak 1 pekerja (20\%), dan kategori umur $\geq 35$ tahun sebanyak 4 pekerja $(80 \%)$.

Setelah dilakukan analisis menggunakan uji Chi-square diperoleh nilai $\mathrm{p}$ value sebesar 0,301 $>a(0,05)$, maka dapat dinyatakan tidak ada hubungan antara umur pekerja dengan kejadian kecelakaan kerja.

2) Masa kerja

Kejadian kecelakaan kerja berat pada kategori pekerja tidak sekolah sebanyak 1 orang $(3,4 \%)$, pendidikan SD 12 pekerja $(41,4 \%)$, pendidikan SMP 7 pekerja $(24,1 \%)$, pendidikan SMA 7 pekerja $(24,1 \%)$, dan kategori pendidikan PT sebanyak 2 pekerja $(6,9 \%)$.

4) APD

Kejadian kecelakaan kerja ringan pada kategori APD tidak lengkap sebanyak 4 pekerja (80\%) dan kategori APD lengkap sebanyak 1 orang $(20 \%)$.

Setelah dilakukan analisis menggunakan uji Chi-square diperoleh nilai $\mathrm{p}$ value sebesar 0,039 < a $(0,05)$, maka dapat dinyatakan Kejadian kecelakaan kerja berat pada kategori suhu tidak memenuhi syarat sebanyak 14 orang memadai sebanyak 80 pekerja $(83,3 \%)$.

\section{Analisis bivariate}

a. Hubungan faktor $\begin{array}{r}\text { manusia } \\ \text { (umur, masa } \\ \text { pendidikan, APD) }\end{array}$
dengan
kecelakaan kerja

\section{1) Umur}

Kejadian kecelakaan kerja sedang pada kategori masa kerja baru sebanyak 14 pekerja (22,6\%), kattegori masa kerja sedang 9 pekerja $(14,5 \%)$, dan kategori masa kerja lama sebanyak 39 pekerja $(62,9 \%)$.

Setelah dilakukan analisis menggunakan uji Chi-square diperoleh nilai $\mathrm{p}$ value sebesar 0,000 $<a(0,05)$, maka dapat dinyatakan ada hubungan antara masa kerja dengan kejadian kecelakaan kerja.

\section{3) Pendidikan}

Setelah dilakukan analisis menggunakan uji Chi-square diperoleh nilai $\mathrm{p}$ value sebesar 0,497 $>a(0,05)$, maka dapat dinyatakan tidak ada hubungan antara pendidikan dengan kejadian kecelakaan kerja.

ada hubungan antara APD dengan kejadian kecelakaan kerja.

\section{b. Hubungan faktor lingkungan kerja (suhu, kebisingan, pencahayaan) dengan kecelakaan kerja}

1) Suhu

(48,3\%), sedangkan untuk kategori suhu memenuhi syarat sebanyak 15 orang $(51,7 \%)$. 
Setelah dilakukan analisis menggunakan uji Chi-square diperoleh nilai $\mathrm{p}$ value sebesar 0,094 Kejadian kecelakaan kerja sedang pada kategori tidak memenuhi syarat sebanyak 57 pekerja (91.9\%), sedangkan pada kategori kebisingan memenuhi syarat sebanyak 5 pekerja $(8,1 \%)$.

Setelah dilakukan analisis menggunakan uji Chi-square

Kejadian kecelakaan sedang pada kategori pencahayaan tidak memenuhi syarat sebanyak 41 pekerja $(66,1 \%)$, sedangkan untuk kategori pencahayaan memenuhi syarat sebanyak 21 orang $(33,9 \%)$.

Setelah dilakukan analisis menggunakan uji Chi-square

diperoleh nilai $\mathrm{p}$ value sebesar 0,714 $>a(0,05)$, maka dinyatakan tidak

Kejadian kecelakaan kerja sedang pada kategori peralatan memadai sebanyak 50 pekerja $(80,6 \%)$, sedangkan untuk kategori tidak memadai sebanyak 12 pekerja $(19,4 \%)$.

Setelah dilakukan analisis menggunakan uji Chi-square diperoleh nilai $\mathrm{p}$ value sebesar 0,118 $>a(0,05)$, maka dapat dinyatakan tidak ada hubungan antara faktor peralatan dengan kejadian kecelakaan kerja.

\section{Pembahasan}

a. Hubungan faktor manusia dengan kecelakaan kerja pada pengrajin gong di Dusun Tihingan, Kabupaten Klungkung Tahun 2018

1) Hubungan umur dengan kecelakaan kerja pada pengrajin gong di Dusun Tihingan, $>a(0,05)$, maka dapat dinyatakan tidak ada hubungan antara suhu dengan kejadian kecelakaan kerja.

\section{2) Kebisingan}

diperoleh nilai $\mathrm{p}$ value sebesar 0,010 < a $(0,05)$, maka dapat dinyatakan ada hubungan antara kebisingan dengan kejadian kecelakaan kerja.

\section{3) Pencahayaan}

ada hubungan antara pencahayaan dengan kejadian kecelakaan kerja.

\section{c. Hubungan faktor peralatan dengan kecelakaan kerja pada pengrajin gong di Dusun Tihingan, Kabupaten Klungkung Tahun 2018}

Kabupaten Klungkung Tahun 2018

Berdasarkan hasil analisis menggunakan uji chi-square didapatkan hasil nilai $\mathrm{P}$ 0,301 yang menunjukkan hasil bahwa tidak ada hubungan antara umur dengan kecelakaan kerja pada pengrajin gong di Dusun Tihingan Kabupaten Klungkung. Responden yang berusia tua lebih banyak mengalami kecelakaan kerja $(58,7 \%)$ daripada responden yang berusia muda $(58,3 \%)$.

2) Hubungan masa kerja dengan kecelakaan kerja pada pengrajin gong di Dusun Tihingan, Kabupaten Klungkung Tahun 2018

Berdasarkan hasil analisis menggunakan chi-square diperoleh $P$-value $0,000<0,05$ yang berarti ada hubungan antara masa kerja dengan kecelakaan kerja pada pengrajin gong di Dusun Tihingan 
Kabupaten Klungkung dengan nilai CC 0,461 yang berarti kedua variabel mempunyai hubungan sedang.

Menurut Geller (2001) faktor pengalaman pada tugas yang sama dan lingkungan sudah dikenal dapat mempengaruhi orang tersebut berperilaku tidak aman dan terus berlaku karena menyenangkan, nyaman, dan menghemat waktu dan perilaku ini cenderung berulang.

Menurut Budiono $(2003)^{4}$ sikap psikologis dan fisik dari seseorang terhadap pekerjaan monoton akan sangat berpengaruh, dimana pekerja yang bersikaf negative dan acuh pada pekerjaannya dapat mengalami bosan, apatis dan mengantuk. Akibat dari kepenatan dan keletihan dari pekerjaan yang terlalu keras, orang yang melakukan pekerjaan monoton akan berkurang tingkat kewasapadaannya setelah melakukan pekerjaan tersebut dengan jangka waktu tertentu.

3) Hubungan pendidikan dengan kecelakaan kerja pada pengrajin gong di Dusun Tihingan, Kabupaten Klungkung Tahun 2018

Berdasarkan hasil analisis menggunakan chi-square diperoleh P-value 0,497>0,050 yang berarti tidak ada hubungan antara pendidikan dengan kecelakaan kerja pada pengrajin gong di Dusun Tihingan Kabupaten Klungkung. Pendidikan formal tertinggi responden adalah SMA yaitu sebesar $41,7 \%$. Karena jenis pekerjaan yang dikerjakan umumnya tidak memerlukan keahlian khusus. Tetapi semakin tinggi tingkat pendidikan seseorang, maka mereka cenderung untuk menghindari potensi bahaya yang dapat menyebabkan terjadinya kecelakaan.

\begin{abstract}
Pendidikan adalah proses seseorang mengembangkan kemampuan, sikap, dan bentukbentuk tingkah laku lainnya di dalam masyarakat tempat ia tinggal, proses sosial yakni orng yang dihadapkan pada pengaruh lingkungan yang terpilih dan terkontrol (khususnya yang datang dari sekolah), sehingga ia dapat memperoleh atau mengalami perkembangan kemampuan sosial dan kemampuan individu yang optimal (Achmad Munib, dkk., 2004). Semakin tinggi tingkat pendidikan seseorang, maka mereka cenderung untuk menghindari potensi bahaya yang dapat menyebabkan terjadinya kecelakaan.
\end{abstract}

4) Hubungan APD dengan kecelakaan kerja pada pengrajin gong di Dusun Tihingan, Kabupaten Klungkung Tahun 2018

Berdasarkan hasil analisis menggunakan chi-square diperoleh P-value $0,039<0,050$ yang berarti ada hubungan antara penggunaan APD dengan kecelakaan kerja pada pengrajin gong di Dusun Tihingan Kabupaten Klungkung dengan nilai CC 0,252 yang berarti kedua variabel memiliki hubungan rendah.

Dari hasil penelitian 96 responden yang di analisis terdapat 83 pekerja yang tidak lengkap menggunakan APD dengan persentase 86,5\%. Dari hasil wawancara dengan pekerja, penggunaan APD yang tidak lengkap disebakan karena perasaan tidak nyaman dan terganggu yang dialami pekerja. Menurut Budiono (2003) perasaan tidak nyaman (risih, panas, berat, terganggu) yang timbul saat menggunakan APD akan mengakibatkan tenaga kerja merasa enggan untuk menggunakannya. 
Keselamatan pekerja harus di prioritaskan, oleh karena itu perlu dipelajari langkah kerja dan alat-alat pelindung untuk menjaga keselamatan pekerja (Bambang endroyono, 1989., dalam Swaputri 2009). Salah satu yang penting dalam mengurangi risiko kecelakaan dari pekerja ialah penggunaan APD. Penggunaan APD yaitu penggunaan seperangkat alat yang digunakan tenaga kerja untuk melindungi sebagian atau seluruh tubuhnya dari adanya potensi bahaya atau kecelakaan kerja. Penggunaan APD tidak secara sempurna dapat melindungi tubuh pekerja, tetapi akan dapat mengurangi tingkat keparahan yang mungkin terjadi (AM. Sugeng Budiono, 2003).

\section{b. Faktor Lingkungan Kerja Dengan Kecelakaan Kerja pada pengrajin gong di Dusun Tihingan, Kabupaten Klungkung Tahun 2018}

1) Hubungan suhu dengan kecelakaan kerja pada pengrajin gong di Dusun Tihingan, Kabupaten Klungkung Tahun 2018

Berdasarkan hasil analisis menggunakan chi-square diperoleh P-value 0,094 > 0,050 yang berarti tidak ada hubungan antara suhu dengan kecelakaan kerja pada pengrajin gong di Dusun Tihingan Kabupaten Klungkung. Hasil analisis dari 96 responden terdapat 59 $(61,5 \%)$ pekerja terpapar dengan suhu yang tidak memenuhi syarat yaitu berkisar antara $31^{\circ} \mathrm{C}-40^{\circ} \mathrm{C}$.

Suhu lingkungan kerja yang tinggi dapat mengakibatkan gangguan kesehatan. Menurut Harninto (1993) dalam Ramdan (2007), seorang tenaga kerja akan dapat mampu bekerja efisien dan produktif bisa lingkungan tempat kerjanya nyaman, atau dapat dikatakan efisiensi kerja optimal dalam daerah nikmat kerja, tidak dingin dan tidak panas. Kondisi lingkungan kerja yang nyaman memungkinkan pekerjaan sehari-hari dapat dikerjakan dengan sebaikbaiknya dan terdapat tempratur yang hampir sama antara metabolism tubuh dan lingkungan sekitarnya (Soewito, 1985 dalam Ramdan 2007). Dimana bagi orang Indonesia cuaca kerja ditempat kerja yang dirasakan nyaman berkisar antara $21^{\circ} \mathrm{C}-30^{\circ} \mathrm{C} \mathrm{ISBB}^{2}$ (Suma'mur, 2013).

2) Hubungan kebisingan dengan kecelakaan kerja pada pengrajin gong di Dusun Tihingan, Kabupaten Klungkung Tahun 2018

Berdasarkan hasil analisis menggunakan chi-square diperoleh $P$-value $0,010<0,050$ yang berarti ada hubungan antara kebisingan dengan kecelakaan kerja pada pengrajin gong di Dusun Tihingan Kabupaten Klungkung dengan nilai CC 0,297 yang berarti kedua variabel memiliki hubungan rendah. ${ }^{2}$ Menurut Peraturan Menteri Tenaga Kerja Dan Transmigrasi Republik Indonesia Nomor PER.13/MEN/X/2011 Tentang Nilai Ambang Batas Faktor Fisika Dan Kimia Di Tempat Kerja, NAB kebisingan di tempat kerja untuk bekerja 8 jam yaitu $85 \mathrm{dBA}$.

Hasil pengukuran tingkat kebisingan tertinggi yang didapat yaitu 89,7 dBA dan tingkat kebisingan terendah yaitu 64,3 dBA selama 8 jam per hari. Tingat kebisingan yang berlebihan dapat memberikan dampak negatif pada tenaga kerja. Menurut Agustian dan 
Samiadi (1993) dalam Ramdan (2007) terdapat gangguan dengar pada frekuensi percakapan yang diakibatkan oleh lamanya paparan bising pada tenaga kerja pabrik tekstil. Pengaruh utama bising adalah kerusakan pada indera pendengar, yang dapat menyebabkan tuli progresif dan lama kelamaan menyebabkan tuli yang bersifat menetap bila terus berada di ruang bising tersebut. Efek kebisingan pada daya kerja adalah timbulnya gangguan komunikasi serta gangguan konsentrasi sehingga dapat menyebabkan kelelahan ${ }^{5}$ (Suma'mur, 1994).

Pengaruh kebisingan tinggi dapat berdampak negatif pada pekerja karena akan mengurangi konsentrasi dalam melakukan pekerjaan yang berisiko tinggi terjadinya kecelakaan kerja seperti pembuatan gong, dimana pekerjanya terpapar dengan suhu dan kebisingan yang tinggi. Oleh karena itu, upaya yang dapat dilakukan untuk mengurangi paparan kebisingan yaitu penggunaan ear muff atau ear plug oleh pekerja.

3) Hubungan pencahayaan dengan kecelakaan kerja pada pengrajin gong di Dusun Tihingan, Kabupaten Klungkung Tahun 2018

Berdasarkan hasil analisis menggunakan chi-square diperoleh $P$-value 0,714 > 0,050 yang berarti tidak ada hubungan antara pencahayaan dengan kecelakaan kerja pada pengrajin gong di Dusun Tihingan Kabupaten Klungkung dengan nilai $\mathrm{CC} 0,083$ yang berarti kedua variabel memiliki hubungan sangat rendah. Hasil analisis dari 96 responden terdapat 66 pekerja $(68,8 \%)$ yang bekerja pada pencahayaan tidak nyaman yaitu kurang dari minimal 100 lux.

Hasil pengukuran intensitas pencahayaan tertinggi yaitu 592,5 lux dan hasil pengukuran intensitas pencahayaan terendah yaitu 13,8 lux $^{6}$. Menurut KEPMENKES RI No. 1405 Tahun 2002 Tentang Persyaratan Kesehatan Lingkungan Kerja Perkantoran Dan Industri pencahayaan adalah jumlah penyinaran pada suatu bidang kerja yang diperlukan untuk melaksanakan kegiatan secara efektif. Dimana NAB untuk jenis kegiatan pekerjaan kasar dan tidak terus menerus yaitu minimal 100 lux.

Pencahayaan yang cukup merupakan salah satu faktor penting untuk keselamatan dalam lingkungan kerja. Beberapa penyelidikan mengenai hubungan antara produksi dan penerangan telah memeprlihatkan bahwa penerangan yang cukup dan diatur sesuai dengan jenis pekerjaan yang harus dilakukan secara tidak lansung dapat mengurangi banyaknya kecelakaan ${ }^{2}$ (Swaputri, 2009). Pencahayaan yang cukup sangat penting dalam proses pembuatan gong, agar pekerja dapat melihat dengan jelas setiap tahapan pekerjaan yang dilakukan dan juga mengurangi risiko kecelakaan akibat pencahayaan yang kurang.

\section{c. Hubungan faktor peralatan dengan kecelakaan kerja pada pengrajin gong di Dusun Tihingan, Kabupaten Klungkung Tahun 2018}

Berdasarkan hasil analisis menggunakan chi-square diperoleh $P$-value $0,118>0,050$ yang berarti tidak ada hubungan antara faktor peralatan dengan kecelakaan kerja pada pengrajin gong di Dusun Tihingan Kabupaten Klungkung 
dengan nilai $\mathrm{CC}$ 0,206 yang berarti kedua variabel memiliki hubungan rendah. Hasil analisis dari 96 responden terdapat 16 pekerja $(16,7 \%)$ menggunakan peralatan yang tidak memadai.

Salah satu peralatan yang berisiko menimbulkan kecelakaan kerja pada proses pembuatan gong ialah tungku yang digunakan untuk proses pembakaran. Dimana pekerja mempunyai jarak yang sangat dekat dengan tungku sehingga diperlukan adanya alat pelindung untuk mengurangi risiko kecelakaan kerja. Alat pelindung dan alat keselamatan pada mesin (Machine Guarding and Safety Devices) adalah semua alat yang dipasang untuk melindungi pekerja dari bahaya langsung maupun tidak langsung yang ada di sutu instalasi. Alat-alat ini bertujuan untuk melindungi pekerja dari bahaya yang diakibatkan oleh mesin, proses ataupun bahan yang ada di instalasi $^{5}$ (Emil Salim, 2002).

\section{SIMPULAN DAN SARAN Simpulan}

Berdasarkan hasil penelitian yang telah dilakukan mengenai faktorfaktor yang berhubungan dengan kecelakaan kerja pada pengrajin gong di Dusun Tihingan Kabupaten Klungkung dapat ditarik simpulan yaitu: Faktor yang menunjukkan adanya hubungan dengan kecelakaan kerja yaitu masa kerja $(0,000)$, APD $(0,039)$, dan kebisingan $(0,010)$. Sedangkan untuk faktor umur $(0,301)$, pendidikan $(0,497)$, suhu $(0,094)$, pencahayaan $(0,714)$, dan faktor peralatan $(0,118)$ secara analisis tidak menunjukkan hubungan yang signifikan dengan kecelakaan kerja.

\section{Saran}

1. Bagi pekerja

Peningkatan kewaspadaan pekerja terhadap timbulnya risiko kecelakaan kerja dengan menggunakan APD secara lengkap untuk peningkatan kemanan dan keselamatan diri.

Upaya pemberdayaan dan pelatihan terhadap pekerja mengenai penggunaan APD dan ketersediaan alat pengaman untuk mengurangi risiko kecelakaan kerja.

\section{Bagi Komunitas}

Upaya pemberdayaan dan intervensi terhadap pekerja mengenai penggunaan APD dan ketersediaan alat pengaman untuk mengurangi risiko kecelakaan kerja.

3. Bagi peneliti selanjutnya

Diharapkan peneliti lain dapat menambahkan faktor-faktor lain seperti faktor ergonomi dalam penelitian ini yang mungkin berhubungan dengan kecelakaan kerja.

\section{DAFTAR PUSTAKA}

Budiono, AM Sugeng. (2003). Bunga Rampai Hiperkes dan $K K$. Semarang: BP UNDIP.

Emil Salim. (2002). Green Company. Jakarta: PT. Astra Internasional Tbk.

Geller, E Scoot. (2001). The Pshychology of Safety Handbook. USA: Lewis Publisher

Helliyanti, Putri. (2009). FaktorFaktor Yang Berhubungan Dengan Perilaku Tidak Aman Di Dept. Utility Ang Operation PT Indofood Sukses Makmur Tbk Divisi 
Bogasari Flour Mills Tahun 2009. Depok: Skripsi UI

Hernawati, Eva. (2008). FaktorFaktor Yang Berhubungan Dengan Kejadian Kecelakaan Kerja Berdasarkan Karakteristik Pekerja Dan Unit Kerja Di Area Pertambangan PT Antam Tbk UPBE Pongkor Bogor Jawa Barat Tahun 2006-2007. Jakarta: Skripsi UIN

Juanda, Juwita.

(2014). Perbandingan Algoritma Naive Bayes Dan Apriori Dalam Sistem Rekomendasi Pemilihan Warna Cat Dinding Kamar Tidur Berdasarkan Kepribadian. Universitas Pendidikan Indonesia. Web: http://repository.upi.edu/1144 8/4/S_KOM_0801361_Chapt er1.pdf (diakses 22 Maret 2018)

Keputusan Menteri Kesehatan Republik Indonesia Nomor 1405/MENKES/SK/XI/2002 Tentang Persyaratan Kesehatan Lingkungan Kerja Perkantoran Dan Industri.

Munib, Achmad dkk. (2004). Pengantar Ilmu Pendidikan. Semarang: UPT UNNES Press.

Nazir, Moh Ph. D. (2003). Metode Penelitian. Jakarta: Ghalia Indonesia

Peraturan Menteri Tenaga Kerja dan Transmigrasi Republik Indonesia Nomor PER.13/MEN/X/2011

Tentang Nilai Ambang Batas Faktor Fisika dan Faktor Kimia di Tempat Kerja.
Profil Desa Tihingan Tahun 2017. Departemen Dalam Negeri. Direktorat Jenderal Pemberdayaan Masyarakat Dan Desa.

Ramdan, M Iwan. (2007). Dampak Giliran Kerja, Suhu dan Kebisingan Terhadap Perasaan Kelelahan Kerja di PT LJP Provinsi Kalimantan Timur. Fakultas Kesehatan Masyarakat. Universitas Mulawarman. Samarinda.

Suma'mur PK. (1994). Hiperkes Keselamatan Kerja dan Ergonomi. Dharma Bakti Muara Agung. Jakarta.

Suma'mur, D. (2013). Higiene Perusahaan dan Kesehatan Kerja (HIPERKES). Jakarta: Sagung Seto.

Swaputri, Eka. (2009). Analisis Penyebab Kecelakaan Kerja (Studi Kasus di PT. Jamu Air Mancur). Jurusan Ilmu Kesehatan Masyarakat. Universitas Negeri Semarang. Web: http://lib.unnes.ac.id/2372/1/4 600.pdf. (diakses tanggal 15 Oktober 2017)

Telan, Albina Bare. (2012). Pengaruh Tekanan Panas Terhadap Perubahan Tekanan Darah Dan Denyut Nadi Pada Tenaga Kerja Industri Pandai Besi Di Desa Hadipolo Kecamatan Jekulo Kabupaten Kudus Jawa Tengah. Program Pascasarjana. Universitas Dipenogero Semarang. Web: http://eprints.undip.ac.id/425 40/1/BAB_I-III.pdf. (diakses tanggal 15 Oktober 2017) 